\title{
A request for directed organ donation in medical assistance in dying (MAID)
}

\author{
Genevieve M. Casey, MSc, MBBS, FRCPC $\cdot$ Michael Kekewich, MA • \\ Viren N. Naik, MD, MEd, MBA, FRCPC • Michael Hartwick, MD, MEd, FRCPC • \\ Andrew Healey, MD, RDCS, RDMS, FRCPC (EM CCM)
}

Received: 23 October 2019/Revised: 4 March 2020/Accepted: 4 March 2020/Published online: 23 March 2020

(C) Canadian Anesthesiologists' Society 2020

In this reflection, we outline a case of a patient wishing to direct their organ donation after receiving medical assistance in dying (MAID). This case challenges our current thinking, guidance, and rules about directed organ donation. We outline some ethical considerations that help frame this case and guide physicians in future cases.

\section{Case}

Ms. P, a 66-yr-old female (who provided consent to this report) with an elevated body mass index and a one-year history of amyotrophic lateral sclerosis (ALS) requested MAID and was approved by two assessors. Her symptoms were progressing rapidly, and she could no longer ambulate or independently provide self-care. She did not have

G. M. Casey, MSc, MBBS, FRCPC ( $\square)$

Division of Geriatrics, Department of Medicine, University of Ottawa, Ottawa, ON, Canada

e-mail: gcasey@toh.ca

\section{Kekewich, MA}

Department of Clinical and Organizational Ethics, The Ottawa Hospital, Ottawa, ON, Canada

V. N. Naik, MD, MEd, MBA, FRCPC

Department of Anesthesiology and Pain Medicine, Faculty of Medicine, University of Ottawa, Ottawa, ON, Canada

\section{Hartwick, MD, MEd, FRCPC}

Divisions of Critical Care and Palliative Medicine, Department of Medicine, University of Ottawa, Ottawa, ON, Canada

Regional Medical Lead, Trillium Gift of Life The Ottawa Hospital, Ottawa, ON, Canada

A. Healey, MD, RDCS, RDMS, FRCPC (EM CCM) Emergency \& Critical Care Medicine, Donation, Trillium Gift of Life Network, Critical Care, William Osler Health System, Hamilton, ON, Canada significant respiratory decline at the time of her assessment and only required minimal oxygen overnight. After being informed that she had been approved, she informed the MAID assessor that following her death she wanted to donate her kidney directly to her daughter. Ms. P and her daughter had had a difficult relationship in previous years, but it had recently improved. She was not interested in nondirected donation, as she preferred a non-hospital-based death with MAID. She was not considered eligible for living donation because her comorbidities would put her at high risk for significant perioperative morbidity and mortality after the donation surgery.

Current state—directed deceased donation

Bill C-14 received Royal assent in June 2016 permitting MAID as an exception to the criminal code. ${ }^{1}$ From February to June 2016, MAID was only available through a special court approval process. As of October 2018, it is estimated that over 6,749 Canadians have undergone MAID, representing approximately $1.12 \%$ of all Canadian deaths. ${ }^{2}$ Federal reporting requirements changed and updated national statistics are expected in spring $2020 .^{2}$

In Canada, legislation permitting organ and tissue donation is provincially based but adheres to federal law and national practice standards. In Ontario, Trillium Gift of Life Network (TGLN) is the provincial organ donation organization, and in 2018 it coordinated organ donations from 333 deceased donors. ${ }^{3}$ Ipsos Reid has previously published survey data indicating an overwhelming $81 \%$ of Canadians would be willing to donate their organs in the case of their death. ${ }^{4}$ Since MAID has been legalized, up until January 2019 there have been 56 patients who have requested assessment for organ donation, and 30 patients who have donated organs that have been successfully transplanted following MAID in Ontario, British 
Columbia, and Quebec. ${ }^{5}$ These patients donate following confirmation of death by circulatory criteria (i.e., donation after cardiac death). This topic, donating organs after MAID, has recently been thoughtfully discussed in Dr. Rosenbaum's article 'Altruism in extremis - the evolving ethics of organ donation'. 6

Currently, organs are allocated to a recipient using an organ allocation algorithm that considers many items including medical urgency, amount of time on the waitlist, size of the organ, blood type, and other factors to ensure the distribution of the organ is based on fair criteria. $^{7}$ Since 2010, the waitlist for organ transplant in Ontario has been relatively constant between 1,500 and 1,600 , but the need is likely even greater as many patients waiting for transplantation have not yet been listed (e.g., dialysis patients). ${ }^{3}$

Directed living donation is permitted by transplant programs and is actually promoted as a strategy for recipients at the time of listing. For example, an individual could donate their kidney to a person of their choosing as long as they follow the principles of TGLN's policy for directed donation. This is managed primarily by individual hospital-based transplant programs. Between 2016 and 2018, the number of living donations has remained relatively stable at approximately 260 per year. ${ }^{3}$ Similar to living donation, organ and tissue donation after MAID occurs following first person consent from a conscious competent patient, but differs in that the donation occurs after death.

With MAID provisions increasing, and Canadians' general support for organ donation, we anticipate seeing a rise in requests for directed donation in the setting of MAID, which may give rise to a number of ethical challenges.

\section{Ethical challenges_-autonomy and vulnerability}

Federal legislation concerning MAID in Canada includes a number of safeguards to ensure that any decision to pursue MAID is autonomous, a concept which we will explore further on in this article. While none of these safeguards are particularly unique to MAID, the collective processes outlined in Bill C-14 are clearly designed to protect against concerns that a patient might be coerced or pressured toward pursuing MAID. Reasons for coercion could include a lack of information on the alternatives to MAID, or potential secondary gain from family, friends, or healthcare professionals involved in the care of the patient. A number of these safeguards are outlined in section 241.2 (1) of Bill C-14, including requirements that a patient be capable of making decisions, that the request for MAID is voluntary and not the result of external pressure, and that informed consent is provided. ${ }^{8}$ Taken together, these protections conjure an image of the patient as a free individual whose decision-making is not contaminated by factors external to themselves. This is further evidenced by other legislative requirements. Most notably, beneficiaries are even excluded from being independent witnesses to a person's written request for MAID. The overarching objective is intended to be the maintenance of truly independent or autonomous decisionmaking.

While this objective is aspirational, it raises interesting questions about the nature of patient autonomy, and how it should be respected. These questions have also been the subject of academic interest, as many scholars have reexamined the basic concept of respect for autonomy through new lenses, including relational autonomy. Arguably, Bill C-14 aligns with a historical view of autonomy that is individualistic. Anne Donchin describes this understanding of independence in her paper on autonomy, interdependence, and assisted dying:

According to the conception of personal autonomy implicit in this model of agency, individuals are separated from one another by sharp boundaries that can be justifiably breached only by the consent of self-determining subjects. This contract-like picture of human relations has come under increasing scrutiny in recent years, but it still operates as the leading paradigm structuring professional-client relations, particularly between healthcare providers and patients. ${ }^{9}$

Relational autonomy treats personal relationships and their social environment as a part of a person's identity and their decision-making process, instead of a threat to independent decision-making. To put this into context, if one reflects on the major decisions made in life (e.g., moving to a new city, purchasing a house) it is not difficult to perceive how the decision was impacted by one's personal relationships and social environment. Importantly, this does not legitimize coercion or other hostile influences, but opens the door to understanding autonomy as more nuanced and socially determined.

The nuances around autonomy are particularly important when considering vulnerability. During the development of the MAID regulations, lawmakers and interest groups spent significant time considering vulnerability and trying to ensure that vulnerable individuals (because of medical conditions, environment, or societal constructs) were not "induced to suicide". 10 Indeed, Bill C- 14 tries to minimize vulnerability through restrictions on access for mature minors, those with solely psychiatric illnesses, and those requesting MAID through advance care plans. 
Objectionable paternalism should also be considered when attempting to balance autonomy and vulnerability. This is described as circumstances where groups identified as vulnerable are treated as incompetent, are marginalized, are not included in decision-making, or are infantilized in an attempt to reduce risks to society. ${ }^{11}$ Paternalism may also be objectionable when it involves a blanket assertion that a group of people are vulnerable and unable to exercise autonomy, rather than approaching then as individuals who are relationally embedded in different ways. These assertions risk disregarding the fact that vulnerability is a universal human experience that is not incompatible with some conceptions of autonomy. Being vulnerable does not mean a person cannot be autonomous. Whether Bill C-14 suffers inherently from objectionable paternalism or not requires broader conversation. Nevertheless, when considering organ donation following MAID, one must consider that these individuals may be influenced by factors external to themselves and their belief system.

In particular, patients wishing to donate organs as part of the MAID process are a population that might be considered vulnerable and in need of protection given perceived threats to their autonomy. Organ donation represents an interesting issue with respect to autonomy and vulnerability, because the act of donation necessarily implicates the interests of at least one other party-i.e., the organ recipient(s). In terms of autonomy in the individual sense, this poses a problem. The patient is expected to consider their own values, interests, and preferences in relation to their own condition and circumstances. The possibility of donation, by definition, extends beyond that through a form of altruism or generosity, which could result in the act of donation being better captured by the concept of relational autonomy.

With patients wishing to donate organs after MAID, concerns about vulnerability can arise in a variety of ways. Currently, once a patient has been approved for MAID, they are informed of non-directed donation of organs and tissues by a healthcare professional. Healthcare professionals are not supposed to raise the discussion about organ donation until after MAID approval and this discussion happens subsequent to, and separately from, the request for MAID. This is to ensure that the decision to pursue MAID is not unduly contaminated by a decision to pursue donation, or that the patient does not feel compelled to donate as a condition of receiving MAID. Nevertheless, this does not prevent a patient from considering donation in their end of life care plan independently.

The case depicted in the introduction creates challenges that require further thinking and care. In the case of a patient wishing to direct donation, apprehension by the healthcare team (or even society) about coercion or undue infringement of autonomy is heightened significantly. Awareness of this is critically important to the integrity of both processes. The patient in this circumstance might clearly meet MAID criteria related to their medical condition and suffering, but the desire to donate organs for the benefit of a loved one might still be a motivating factor. Should a patient like this be eligible for MAID? Should this patient be permitted to direct the donation? What if the patient changes their mind about MAID but still feels compelled to donate their organ to their daughter? Notwithstanding the current policies and legislation, there are no easy or "right" answers.

\section{Conclusions}

Given Canadians general support for organ donation, the unrelenting need for organs for transplant, and MAID becoming a more popular end of life option, we believe that there will likely be an increase in directed donation in the setting of MAID. In fact, at the conclusion of Dr. Rosenbaum's article, a case is disclosed of Ms. J, a nurse with ALS who proceeded with MAID and directed her kidney to a friend. ${ }^{6}$

As per current working policy of TGLN and as advised by the recently published joint guidance for policy from Canadian Blood Services, the Canadian Critical Care Society, the Canadian Society of Transplantation, and the Canadian Association of Critical Care Nurses, ${ }^{11}$ we agree that the assessment for MAID and the assessment for nondirected donation should be separate conversations and processes. Their guidance states that directed donation should neither be offered nor encouraged. ${ }^{12}$ Wellintentioned as this statement is, we already see by Ms. J and Ms. P that it perhaps lacks real-world applicability. Directed donation presents a unique challenge that must be dealt with carefully on an individual basis to maintain public trust and integrity in the system.

We recognize that these scenarios will be challenging for MAID assessors to assess the patient's autonomy and vulnerability and encourage them to be aware of the principles of relational autonomy and objectionable paternalism.

Therefore, the authors recommend the following principles and guidance:

- The assessment for MAID eligibility is guided by legislation and remains completely independent of the assessment for donation.

- If the patient is eligible for MAID, the assessment for medical suitability to donate should proceed. 
- For medically suitable patients wishing to direct their donation, the assessors for MAID should be notified by the patient themselves or the other assessor.

- Two questions should then be considered by the patient and the assessors in an attempt to exclude coercion: 1) If donation were not possible, would the patient still request MAID? 2) If directed donation were not possible, would the patient still request MAID?

- The authors conclude that if the MAID assessors feel that answers to these questions do not indicate coercion, and the patient remains eligible, they should be permitted to direct their organ donation respecting the principles of agency and autonomy.

- The authors also advise organ donation committees to constantly revisit every mechanism to ensure that every patient feels free up to the last moment to change their mind and respect their autonomy of choice if they meet requirements for donation.

Additionally, these cases could set precedent for advanced care planning that is not currently allowed. For example, one cannot direct your organ donation upon death from natural causes. By allowing it for MAID, will individuals want to direct their organ donation in circumstances of their natural death via advanced directives?

\section{Case outcome}

The patient did contact TGLN to assess her eligibility to donate her kidney to her daughter. She underwent some blood tests. Directed donation was not possible as her recipient did not have a compatible blood type. She received MAID a few months after her assessment in her residence with close friends and family in attendance.

Despite the donation not proceeding, the daughter's role in this case cannot be underestimated. Would the daughter's need for the organ have expedited or delayed the MAID process? Would the daughter have preferred more time with her mother at the risk of her own health deteriorating?

Ms. P's decision to pursue investigations to determine whether she could be an organ donor for her daughter provides an example of the nuances between individual autonomy versus relational autonomy. The patient decided to proceed with MAID as her preferred end-of-life option (individual autonomy), and knowing that her daughter could potentially benefit from her foreseeable death, she concurrently investigated directed organ donation (relational autonomy). While it is impossible to know what would have happened if she had been a match, the assessors' in this case did feel that she should be allowed to direct her donation.

\section{Conflicts of interest None.}

Funding statement No funds were received for this study.

Editorial responsibility This submission was handled by Dr. Hilary P. Grocott, Editor-in-Chief, Canadian Journal of Anesthesia.

\section{References}

1. House of Commons Canada. Bill C-14 - 2016. Available from URL: https://www.ourcommons.ca/en (accessed March 2020).

2. Government of Canada. Fourth Interim Report on Medical Assistance in Dying in Canada. Ottawa, ON: Health Canada; 2019. Available from URL: https://www.canada.ca/en/healthcanada/services/publications/health-system-services/medicalassistance-dying-interim-report-april-2019.html (accessed March 2020).

3. Trillium Gift of Life Network. Statistics. Available from URL: www.giftoflife.on.ca (accessed March 2020).

4. Ipsos Reid. Canada Speaks, Most Canadians (81\%) willing to donate their organs in the case of their death - 2006. Available from URL: https://www.ipsos.com/sites/default/files/publication/ 2006-07/mr060711-1.pdf (accessed March 2020).

5. Ball IM, Healey A, Keenan $S$, et al. Organ donation after medical assistance in dying - Canada's first cases. N Engl J Med 2020; 382: $576-7$.

6. Rosenbaum L. Altruism in extremis - the evolving ethics of organ donation. N Engl J Med 2020; 382: 493-6.

7. Trillium Gift of Life Network. Resources for Health Care Professionals. Available from URL: https://www.giftoflife.on. ca/en/professionals.htm\#waitlistorganpolicies (accessed March 2020).

8. Parliament of Canada. Statutes of Canada 2016, chapter 3. Bill C-14 (Royal Assent) June 17, 2016. Available from URL: https:// www.parl.ca/DocumentViewer/en/42-1/bill/C-14/royal-assent (accessed March 2020).

9. Donchin A. Autonomy, interdependence, and assisted suicide: respecting boundaries/crossing lines. Bioethics 2000; 14: 187204.

10. Chochinov HM, Frazee C. Finding a balance: Canada's law of medical assistance in dying. Lancet 2016; 388: 543-5.

11. Mackenzie C, Rogers W, Dodds S. Vulnerability: New Essays in Ethics and Feminist Philosophy (Studies in Feminist Philosophy). Oxford: Oxford University Press; 2014. p. 48.

12. Downar J, Shemie SD, Gillrie C, et al. Deceased organ and tissue donation after medical assistance in dying and other conscious and competent donors: guidance for policy. CMAJ 2019; 191: E604-13.

Publisher's Note Springer Nature remains neutral with regard to jurisdictional claims in published maps and institutional affiliations. 